\title{
Transient Edematous Lesions of the Splenium in Epileptic Patients
}

\author{
Giovanna Carrara, Edoardo Ferlazzo, Donatella Tampieri, \\ Frederick Andermann, Denis Melanson
}

\begin{abstract}
Background: Transient focal lesions in the splenium of the corpus callosum (SCC) have been previously described in patients with epilepsy or without epilepsy but receiving antiepileptic drugs (AED). Case reports: Two epileptic patients were admitted to our long-term monitoring unit. Antiepileptic drugs were completely discontinued a few days later. One patient had no seizures. The other had three attacks, the last of which occurred two days before a brain magnetic resonance imaging (MRI) was performed. In both cases brain MRI showed a lesion in the SCC characterized by high signal on T2-weighted images and no enhancement after Gadolinium infusion. The patients were discharged with their pre-admission medications. A follow-up MRI five weeks later showed resolution of the SCC lesions. Conclusions: The pathogenesis of transient SCC lesions in epileptic patients is still unclear. In our patients, either the sudden AED withdrawal or the seizures activity may be presumed to be the cause, though an individual susceptibility must also be considered.
\end{abstract}

RÉSUMÉ: Lésions oedémateuses focales transitoires dans le bourrelet du corps calleux chez les épileptiques. Introduction: Des lésions focales transitoires dans le bourrelet du corps calleux (BCC) ont déjà été décrites chez des patients épileptiques ou des patients sans épilepsie qui recevaient des médicaments anti-épileptiques (MAÉ). Étude de cas: Les médicaments anti-épileptiques ont été cessés complètement après quelques jours d'observation chez deux patients épileptiques admis à notre unité de surveillance prolongée. Un patient n'a pas eu de crise. L'autre a eu trois crises, la dernière étant survenue deux jours avant l'IRM cérébral. Chez les deux patients, l'IRM cérébral a montré une lésion du BCC caractérisée par un signal intense sur les images pondérées T2 et aucun rehaussement après infusion de gadolinium. Les patients ont quitté l'hôpital avec la même médication qu'ils prenaient avant leur admission. L'IRM faite cinq semaines plus tard a montré une résolution des lésions du BCC. Conclusions: La pathogenèse des lésions transitoires du BCC chez les patients épileptiques demeure obscure. Chez nos patients, bien qu'une susceptibilité individuelle doive être envisagée, le retrait soudain des MAÉ ou l'activité critique pourrait être en cause.

Can. J. Neurol. Sci. 2005; 32: 352-355

Transient focal lesions in the splenium of the corpus callosum (SCC) have been described in patients with epilepsy or without epilepsy receiving antiepileptic drugs (AEDs). ${ }^{1-6}$ The nature of these lesions remains unclear. Magnetic resonance imaging (MRI) showed oval lesions hyperintense on T2-weighted images with no enhancement on post-contrast images and complete reversibility without specific treatment. The etiology of these presumably edematous lesions is still uncertain.

\section{REPORT OF TWO CASES}

\section{Patient 1}

A 34-year-old woman with a 13-year history of intractable temporal lobe epilepsy was admitted for pre-surgical evaluation. Daily AED were carbamazepine $800 \mathrm{mg}$, clonazepam $1.5 \mathrm{mg}$ and clobazam $10 \mathrm{mg}$ with good serum levels. At the age of 31 , she was diagnosed to have a paranoid psychosis for which she received olanzapine, $15 \mathrm{mg}$ daily. There was no history of alcohol abuse or nutritional deficiency. The neurological examination was normal. Routine laboratory tests and serum liver enzymes were normal. The EEG showed independent epileptic discharges over both temporal regions. During 15 days of

From the Department of Radiology, McGill University, Montreal Neurological Institute and Hospital, Montreal, QC, Canada.

ReCEIVED August 16, 2004. ACCEPTED IN FInAL fORm FEBRuary 15, 2005. Reprint requests to: Donatella Tampieri, Department of Radiology, McGill University, Montreal Neurological Institute and Hospital, 3801 University Street, Montreal, QC H3A 2B4, Canada. 


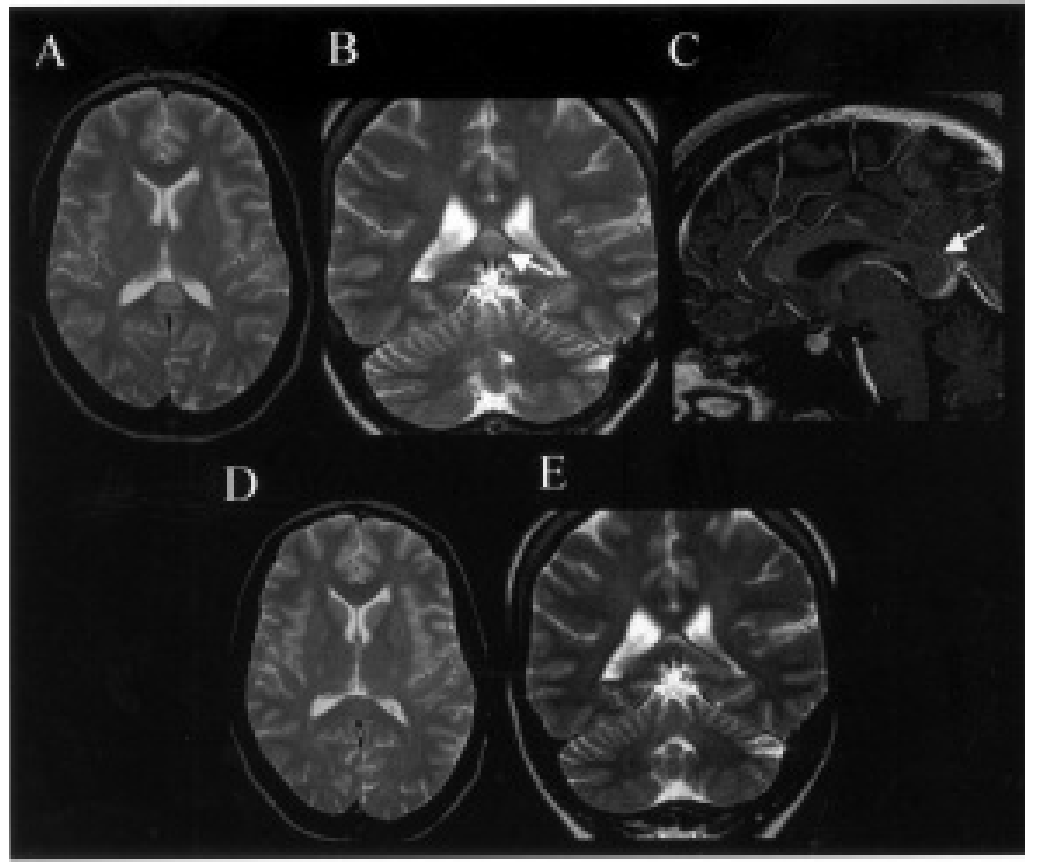

Figure 1: A-E Patient 1: (A) Axial T2-weighted spin-echo image and coronal T2weighted FSE image (B) Shows an ovoid hyperintense lesion (arrows) in the splenium of the corpus callosum. (C) Sagittal T1-weighted post-gadolinium image shows a circumscribed nonenhancing hypointense lesion (arrow) in the splenium of the corpus callosum. (D-E) Follow-up MRI five weeks after the initial MR examination shows almost complete resolution of the focal hyperintense lesion of the SCC in axial T2- and coronal T2-weighted images

monitoring she had no seizures despite discontinuation of clobazam on the third day, carbamazepine on the sixth day and clonazepam on the 13th day. Brain MRI revealed a homogenous round shaped lesion in the SCC (Figure 1, A-C). The lesion displayed an increased signal intensity in proton density (PD), weighted images (T2) and fluid attenuated inversion recovery (FLAIR) images. The T1-weighted images showed slightly reduced signal abnormality that did not enhance after gadolinium infusion. No other abnormalities were found.

There was no evidence of disconnection syndrome on neurological examination. She was discharged with her pre-admission medications and a follow-up MRI five weeks later demonstrated almost complete resolution of the SCC lesion (Figure 1, D-E). The patient had no seizures during this time interval.

\section{Patient 2}

This is a 35-year-old man with an intractable epileptic disorder since the age of 30 who was admitted for diagnostic evaluation. Brain MRI performed five months before showed no significant abnormalities. On admission he received carbamazepine 1.6 gr with a therapeutic serum level. Medical and family history was unremarkable, with no history of alcohol abuse or nutritional deficiency. Neurological examination, routine laboratory tests and serum liver enzymes were normal. Carbamazepine was discontinued on the second day. Interictal EEG showed rare, generalized epileptic abnormalities. During the first week of admission he had three generalized seizures. An MRI examination performed 48 hours after the last seizure demonstrated a lesion in the SCC with signal characteristics identical to those described for the first patient (Figure 2, A-C). Follow-up MRI five weeks later showed resolution of the lesion (Figure 2, D-E). The patient had no seizures during this time interval and he was discharged on carbamazepine 1.6 gr and clobazam $10 \mathrm{mg}$ per day.

\section{DisCUSSION}

The cause of transient focal lesions in the SCC has not been identified. Originally these were thought to represent transient focal edema due to transhemispheric transmission of seizure activity in patients with frequent attacks and secondary generalization ${ }^{1}$. Kim et al. ${ }^{2}$ reported such lesions in six patients with complex partial seizures, only one of whom had secondary generalization. They suggested that the lesions were related to intramyelinic edema and that AED toxicity, especially due to phenytoin and vigabatrin, was responsible. Polster et al. ${ }^{3}$ found such abnormalities in three epileptic patients admitted for presurgical evaluation in whom AED were abruptly reduced. They argued that a dysequilibrium in fluid balance induced by rapid changes in AED serum concentration, along with vitamin B12 and folate deficiency, were involved in the generation of the 


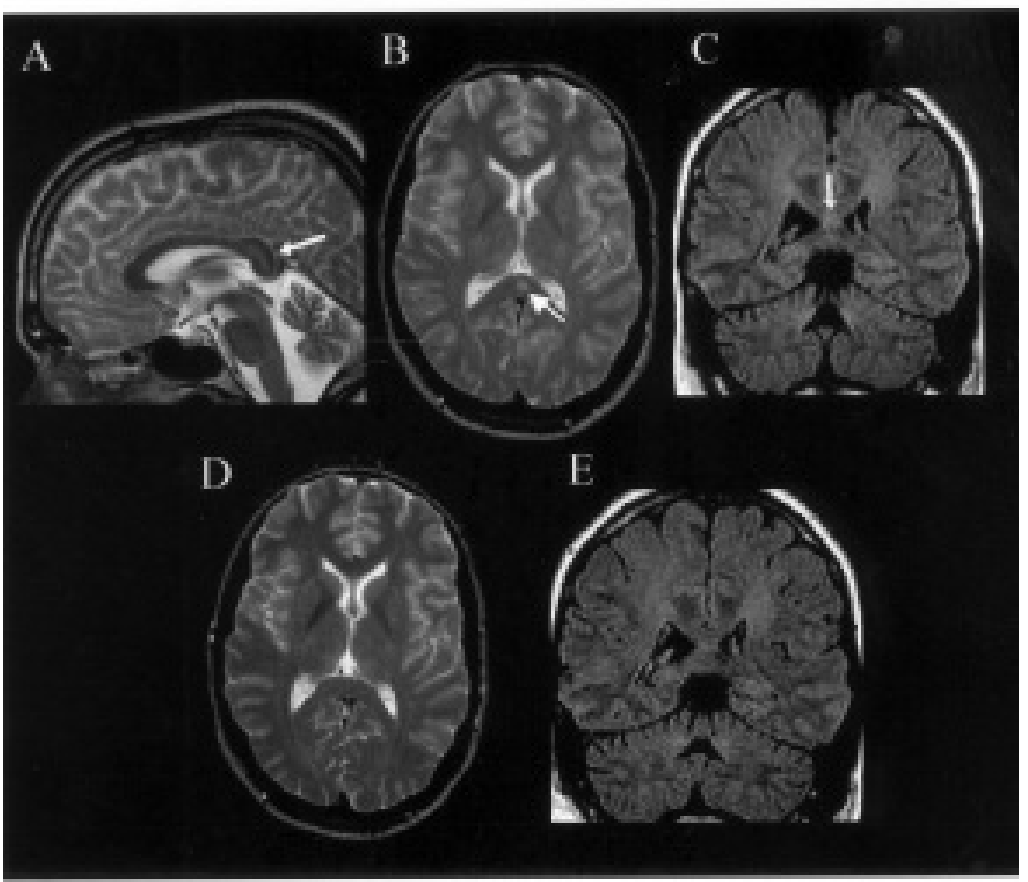

Figure 2: A-E Patient 2: Sagittal (A) and Axial (B) T2-weighted and coronal FLAIR (C) images show a focal hyperintense lesion (arrows) in the splenium of the corpus callosum. D-E. Follow up MRI five weeks after the initial MR examination show complete resolution of the focal hyperintense lesion of the SCC in axial T2-weighted and coronal FLAIR images.

lesions. More recently, Gurtler et al. ${ }^{4}$ found these abnormalities in 16 patients admitted for presurgical EEG-monitoring. They argued that a rapid and relatively prolonged reduction of AED in the presence of a minimal metabolic disturbance may be responsible. Maeda et al..$^{5}$ reported a similar abnormality in a depressed patient who received carbamazepine and valproate as mood stabilizers. The lesion disappeared after their discontinuation. This patient had no epilepsy. They interpreted the signal on diffusion-weighted MRI to represent cytotoxic edema.

In these patients SCC lesions due to other causes such as Marchiafava-Bignami disease, multiple sclerosis, tumor, human immunodeficiency virus (HIV) infection, encephalitis and infarct, were unlikely, given their past histories, the neurological evaluations, the laboratory and neurophysiological findings, the MRI imaging and the reversibility of the signal abnormality. The MRI features suggest the presence of a transient edematous phenomenon, either cytotoxic or vasogenic, but different pathogenetic mechanisms may be involved in their development. AED toxicity is unlikely since the serum concentrations on admission were within the normal range and they were discontinued several days before the MRI. In addition, the lesions nearly completely disappeared despite reintroduction of the drugs. In the first patient, who had no attacks during 15 days of monitoring, seizure activity was unlikely to be the cause. Therefore, we argue that the lesion may be due to abrupt discontinuation of the AEDs as suggested by Polster et al. ${ }^{3}$ and Gurtler et al. ${ }^{4}$ The second patient had three generalized seizures during the monitoring, the last occurring 48 hours before the MRI was performed. Either the seizure activity or the AED withdrawal or both, may have been the cause of the SCC lesion in this patient.

In conclusion, it appears that in the population of patients with epilepsy or treated with AED, different pathogenetic mechanisms might be at the origin of SCC lesions. Since these lesions are rare despite large number of patients studied, an individual susceptibility, either genetic or acquired (i.e. vitamin deficiency), must play an important role in their development. It is important to be aware of the benign nature of the lesions in this population to avoid needless invasive diagnostic procedures and incorrect medical or surgical treatment. Though pathoclisis, (specific affinity of certain toxins for certain organs) due to metabolic disorders is known (i.e. Marchiafava-Bignami, central pontine myelinolysis), the reason for specific splenial involvement, however, in the present condition, remain uncertain. 


\section{REFERENCES}

1. Chason DP, Fleckenstein JL, Ginsburg ML, Mendelsohn DB, Mathews D. Transient splenial edema in epilepsy: MR imaging evaluation. Proceedings of the 34th Annual Meeting of the American Society of Neuroradiology: June 21-27, 1996; Seattle. Chicago: Old Smith Printers, 1996.

2. Kim SS, Chang K, Kim ST, et al. Focal lesion in the splenium of the corpus callosum in epileptic patients: antiepileptic drug toxicity? AJNR Am J Neuroradiol 1999; 20: 125-129.

3. Polster T, Hoppe M, Ebner A. Transient lesion in the splenium of the corpus callosum: three further cases in epileptic patients and a pathophysiological hypothesis. J Neurol Neurosurg Psychiatry 2001; 70: 459-463.
4. Gurtler S, Ebner A, Woermann FG. Transient lesion in the splenium of the corpus callosum in epilepsy is associated with rapid antiepileptic drug withdrawal. Epilepsia 2004; 45 (Suppl 3): S63.

5. Maeda M, Shiroyama T, Tsukahara H, et al. Transient splenial lesion of the corpus callosum associated with antiepileptic drugs: evaluation by diffusion-weighted MR imaging. Eur Radiol 2003; 13: 1902-1906.

6. Mirsattari SM, Lee DH, Jones MW, Blume WT. Transient lesion in the splenium of the corpus callosum in an epileptic patient. Neurology 2003; 10; 60: 1838-1841. 